We have presented the Graphical Abstract text and image for your article below. This brief summary of your work will appear in the contents pages of the issue in which your article appears.
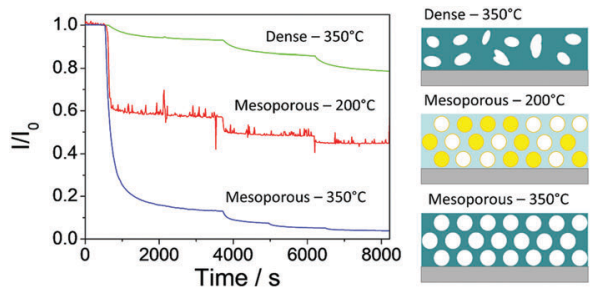

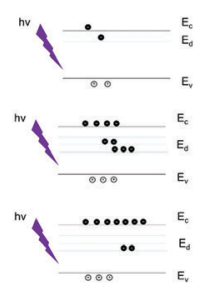

\title{
Mesoscale organization of titania thin films enables oxygen sensing at room temperature
}

Pietro Rassu, Luca Malfatti, Davide Carboni, Maria Casula, Sebastiano Garroni, Emiliano Zampetti, Antonella Macagnano, Andrea Bearzotti* and Plinio Innocenzi*

We developed an oxygen sensor based on mesoporous titania films working at room temperature under UV irradiation. The mesoporous film exhibits a higher response with respect to dense titania, due to the higher surface area and the targer number of surface defects.

Please check this proof carefully. Our staff will not read it in detail after you have returned it.

Proof corrections must be returned as a single set of corrections, approved by all co-authors. No further corrections can be made after you have submitted your proof corrections as we will publish your article online as soon as possible after they are received.

Please ensure that:

- The spelling and format of all author names and affiliations are checked carefully. Names will be indexed and cited as shown on the proof, so these must be correct.

- Any funding bodies have been acknowledged appropriately.

- All of the editor's queries are answered.

- Any necessary attachments, such as updated images or ESI files, are provided.

Translation errors between word-processor files and typesetting systems can occur so the whole proof needs to be read. Please pay particular attention to: tables; equations; numerical data; figures and graphics; and references.

Please send your corrections preferably as a copy of the proof PDF with electronic notes attached or alternatively as a list of corrections - do not change the text within the PDF file or send a revised manuscript. Corrections at this stage should be minor and not involve extensive changes.

Please return your final corrections, where possible within $\mathbf{4 8}$ hours of receipt, by e-mail to: materialsC@rsc.org. If you require more time, please notify us by email. 


\section{Funder information}

Providing accurate funding information will enable us to help you comply with your funders' reporting mandates. Clear acknowledgement of funder support is an important consideration in funding evaluation and can increase your chances of securing funding in the future. We work closely with Crossref to make your research discoverable through the Funding Data search tool (http://search.crossref.org/funding).

Further information on how to acknowledge your funders can be found on our webpage (http://rsc.li/funding-info).

\section{What is Funding Data?}

Funding Data (http://www.crossref.org/fundingdata/) provides a reliable way to track the impact of the work that funders support. We collect funding information from our authors and match this information to funders listed in the Crossref Funder Registry. Once an article has been matched to its funders, it is discoverable through Crossref's search interface.

\section{PubMed Central}

Accurate funder information will also help us identify articles that are mandated to be deposited in PubMed Central (PMC) and deposit these on your behalf.

\section{Providing funder information}

We have combined the information you gave us on submission with the information in your acknowledgements. This will help ensure funding information is as complete as possible and matches funders listed in the Crossref Funder Registry. Please check that the funder names and grant numbers in the table are correct. This table will not be included in your final PDF but we will share the data with Crossref so that your article can be found via the Funding Data search tool.

\begin{tabular}{|l|l|l|}
\hline Funder name & Funder ID (for RSC use only) & Award/grant/contract number \\
\hline & & \\
\hline
\end{tabular}

If a funding organisation you included in your acknowledgements or on submission of your article is not currently listed in the registry it will not appear in the table above. We can only deposit data if funders are already listed in the Crossref Funder Registry, but we will pass all funding information on to Crossref so that additional funders can be included in future.

\section{Researcher information}

If any authors have ORCID or ResearcherID details that are not listed below, please provide these with your proof corrections. Please check that the ORCID and ResearcherID details listed below have been assigned to the correct author. Authors should have their own unique ORCID iD and should not use another researcher's, as errors will delay publication.

Please also update your account on our online manuscript submission system to add your ORCID details, which will then be automatically included in all future submissions. See here for step-by-step instructions and more information on author identifiers.

\begin{tabular}{|l|l|l|l|}
\hline First (given) name(s) & Last (family) name(s) & ResearcherID & ORCID \\
\hline Pietro & Rassu & & \\
\hline Luca & Malfatti & & $0000-0001-6901-8506$ \\
\hline Davide & Carboni & & $0000-0003-2499-4567$ \\
\hline Maria & Casula & & $0000-0002-2973-0002$ \\
\hline Sebastiano & Garroni & & $0000-0001-7686-6589$ \\
\hline Emiliano & Zampetti & & \\
\hline Antonella & Macagnano & & $0000-0002-6015-4832$ \\
\hline Andrea & Bearzotti & & $0000-0002-7513-6581$ \\
\hline
\end{tabular}




\section{Queries for the attention of the authors}

\section{Journal: Journal of Materials Chemistry C}

\section{Paper: c7tc03397d}

\section{Title: Mesoscale organization of titania thin films enables oxygen sensing at room temperature}

For your information: You can cite this article before you receive notification of the page numbers by using the following format: (authors), J. Mater. Chem. C, (year), DOI: 10.1039/c7tc03397d.

Editor's queries are marked on your proof like this Q1, Q2, etc. and for your convenience line numbers are indicated like this $5,10,15, \ldots$

Please ensure that all queries are answered when returning your proof corrections so that publication of your article is not delayed.

\begin{tabular}{|c|c|c|}
\hline $\begin{array}{l}\text { Query } \\
\text { reference }\end{array}$ & Query & Remarks \\
\hline Q1 & $\begin{array}{l}\text { Please carefully check the spelling of all author names. } \\
\text { This is important for the correct indexing and future } \\
\text { citation of your article. No late corrections can be made. }\end{array}$ & $\begin{array}{l}\text { Please change Maria Casula with } \\
\text { Maria F. Casula }\end{array}$ \\
\hline Q2 & $\begin{array}{l}\text { Please check that the Graphical Abstract text fits within } \\
\text { the allocated space indicated on the front page of the } \\
\text { proof. If the entry does not fit between the two horizontal } \\
\text { lines, then please trim the text and/or the title. }\end{array}$ & $\begin{array}{l}\text { We developed an oxygen sensor based on mesoporous } \\
\text { titania films working at RT under UV irradiation. Due to } \\
\text { larger surface area and number of defects, the mesoporous } \\
\text { film exhibits a response higher than dense titania. }\end{array}$ \\
\hline Q3 & $\begin{array}{l}\text { The sentence beginning "The prospect..." has been } \\
\text { altered for clarity. Please check that the meaning is } \\
\text { correct. }\end{array}$ & No Remarks \\
\hline Q4 & $\begin{array}{l}\text { The sentence beginning "These pores..." has been } \\
\text { altered for clarity. Please check that the meaning is } \\
\text { correct. }\end{array}$ & No Remarks \\
\hline Q5 & $\begin{array}{l}\text { In the sentence beginning "In the titania..." should } \\
\text { "measures" be changed to "measurements"? }\end{array}$ & $\begin{array}{l}\text { Yes. Please change "measures" to } \\
\text { "measurements". }\end{array}$ \\
\hline Q6 & $\begin{array}{l}\text { The sentence beginning "The organization..." has been } \\
\text { altered for clarity. Please check that the meaning is } \\
\text { correct. }\end{array}$ & $\begin{array}{l}\text { We agree with the suggested revisions. } \\
\text { Additionally, in line } 46, \text { please change } \\
\text { "micelle" with "micelles". }\end{array}$ \\
\hline Q7 & $\begin{array}{l}\text { Please note that a conflict of interest statement is required } \\
\text { for all manuscripts. Please read our policy on Conflicts of } \\
\text { interest (http://rsc.li/conflicts) and provide a statement } \\
\text { with your proof corrections. If no conflicts exist, please } \\
\text { state that "There are no conflicts to declare". }\end{array}$ & There are no conflicts to declare \\
\hline
\end{tabular}


10

Cite this: DOI: 10.1039/c7tc03397d

\section{Mesoscale organization of titania thin films enables oxygen sensing at room temperature}

\author{
Pietro Rassu, ${ }^{a}$ Luca Malfatti, (D) a Davide Carboni, (D) a Maria Casula, iD b \\ Sebastiano Garroni, ${ }^{c}$ Emiliano Zampetti, ${ }^{d}$ Antonella Macagnano, ${ }^{d}$ \\ Andrea Bearzotti (iD *d and Plinio Innocenzi (iD *a
}

Received 28th July 2017, Accepted 10th October 2017

DOI: $10.1039 / \mathrm{c} 7 \mathrm{tc0} 03397 \mathrm{~d}$

rsc.li/materials-c
The application of titania materials to gas sensing devices based on thin films are of limited utility because they only operate at a high working temperature and exhibit in general a low sensitivity. To overcome these constraints, a new type of oxygen sensor based on mesoporous titania thin films working at room temperature under UV irradiation has been developed. The increased density of charge carriers induced by the photoconductive effect, has been used to enhance the sensitivity of the thin oxide layers. Mesostructured titania films have been prepared via self-assembly and thermal processing to remove the organic template obtaining anatase nanocrystals. The mesoporous films show a striking decrease of the current in the presence of oxygen that acts as an electron scavenger. Mesoporous samples exhibit a much higher response with respect to dense titania, due to the higher surface area and the larger number of surface defects.

\section{Introduction}

30 Semiconductive nanocrystalline titania films have been extensively used as resistive, ${ }^{1}$ capacitive $^{2}$ and optical ${ }^{3}$ sensors for a large variety of gases and volatile compounds. ${ }^{4,5}$ Differences in crystalline structure, crystalline dimension and surface defects ${ }^{6}$ have been observed to affect the titania sensing capability 35 in terms of sensitivity and detection rate. These traditional sensing systems, however, have some drawbacks which are the high cost for optical systems or the high operation temperature

Q3 for resistive titania sensors. ${ }^{7-9}$ The prospect for obtaining sensing titania as thin layers is also important because it can

40 be easily integrated into a Micro-Electro-Mechanical System with respect to thick films. ${ }^{10,11}$

More recently the well-known photocatalytic properties of titania have been used to produce better performing sensing devices. ${ }^{4}$ The absorption of photons generated by an external UV excitation source increases, in fact, the population of electrons in the titania conduction band causing an enhancement of the

\footnotetext{
${ }^{a}$ Laboratory of Materials Science and Nanotechnology, D.A.D.U., CR-INSTM, Università di Sassari. Palazzo Pou Salit, Piazza Duomo 6, 07041 Alghero (SS), Italy.E-mail: plinio@uniss.it

${ }^{b}$ Department of Chemical and Geological Sciences, University of Cagliari, S.S. 554 bivio per Sestu, 09042 Monserrato (CA), Italy

${ }^{c}$ Universidad de Burgos, International Research Centre in Critical Raw MaterialsICCRAM, Plaza Misael Bañuelos s/n 09001, Burgos, Spain

${ }^{d}$ Institute of Atmospheric Pollution Research-National Research Council (CNR-IIA), Via Salaria km 29300 Montelibretti, 00016 Roma, Italy.

E-mail: a.bearzotti@iia.cnr.it
}

electronic conduction in the materials. This is reflected by an increased ability to detect small differences in the environment close to the sensing layer.

Among the different techniques used to fabricate titania films, the deposition of thin layers by the liquid phase offers a better control of the crystallites at the nanoscale. ${ }^{12,13}$ One of the simplest synthesis routes is self-assembly of a colloidal dispersion of anatase and rutile nanoparticles. This strategy allows for controlling the size, shape and relative concentration of the two phases, however the nanocrystals should be pre-formed in the solution before preparing the coatings.

An interesting possibility for further improvement of the sensing properties is offered by mesoporous thin films. ${ }^{14}$ Titania dense films, in fact, are in general not very efficient sensors because of the limited sensing surface area ${ }^{15}$ and limited control of the crystalline structure. The mesoporous structure offers several advantages in sensing applications ${ }^{16-18}$ in comparison to dense films because the ordered pores allow for a more efficient diffusion. Moreover, the smaller size of the anatase crystallites increases the oxidizing and reducing capability while separation of the photogenerated hole/electron pairs becomes also more efficient. The organization at the mesoscale can be easily achieved through the self-assembly of supramolecular templates that produces an organized arrays of organic micelles into the as-deposited titania films. The organic template is removed by a mild temperature thermal calcination that leaves an organized mesoporosity of monodispersed pores with an average size of $\approx 5 \mathrm{~nm}$. The growth of nanocrystalline titania in such a highly porous organized structure is sterically 
1 limited by the thickness of the $\mathrm{TiO}_{2}$ pore walls, so that, until the porosity is preserved, the crystallite size is homogeneously controlled throughout the matrix. ${ }^{19}$ The heat treatment controls the crystal growth and the mesoporosity, temperatures higher than $400{ }^{\circ} \mathrm{C}$ produce collapsing of the pores and coarsening of the titania nanocrystals.

In this work we have developed an oxygen chemosensor stimulated by UV light using a nanocrystalline mesoporous titania film as the sensing layer. ${ }^{20-22}$ Recently, the growing 10 demand for low oxygen concentration sensors has been promoted by their biological research, clinical and medical applications, and process control in the chemical industry. ${ }^{23}$ Titania based sensors can take advantage of the high electronic current generated by the photoconductive effect of titania that is 5 quenched by the adsorbed oxygen. Titania, and more generally oxide materials, require a high temperature to activate their detection capability $\left(300-1000{ }^{\circ} \mathrm{C}\right)$ which is reflected in the large energy consumption necessary to heat the semiconductor. Moreover the high working temperature poses safety issues when the sensor is used in environments containing explosive gases. Our sensor has therefore been developed to offer a possible solution to these main issues. The UV-stimulated titania mesoporous sensors have, in fact, intrinsic advantages for working at room temperature and for fabrication as thin film.

\section{Experimental section}

\section{Chemicals}

$\mathrm{TiCl}_{4}$ (Sigma, >99\%), ethanol (Sigma-Aldrich, >99\%), water (milli-Q), triblock copolymer Pluronic F-127 (PEO106-PPO70PEO106, Aldrich) were used as received without further purification.

\section{Preparation of the interdigitated electrodes}

Interdigitated electrodes (IDE) consisting of electrodes with a gap of $20 \mu \mathrm{m}, 100 \mathrm{~nm}$ thickness and $20 \mu \mathrm{m}$ width, were prepared by the physical vapour deposition of platinum on passivated silicon substrates $(8 \times 9 \times 0.4 \mathrm{~mm})$.

\section{Synthesis of mesoporous titania films}

$\mathrm{TiCl}_{4}$ was dissolved under stirring in anhydrous ethanol using the molar ratio: $\mathrm{TiCl}_{4}: \mathrm{EtOH}=1: 10$. This solution was further diluted with ethanol, Pluronic $\mathrm{F} 127$ and $\mathrm{H}_{2} \mathrm{O}$ and left under stirring for 2 hours with the molar ratio $\mathrm{TiCl}_{4}$ : $\mathrm{EtOH}: \mathrm{H}_{2} \mathrm{O}$ :

$45 \quad \mathrm{~F} 127=1: 69.7: 15.5: 4 \times 10^{-3}$. A similar precursor sol, without the addition of the surfactant, was used to prepare the dense titania samples. Thin films were deposited by dip-coating maintaining the relative humidity ( $\mathrm{RH}$ ) constantly below $26 \%$ and the temperature at $25{ }^{\circ} \mathrm{C}$ in the deposition chamber over in the precursor solution for $30 \mathrm{~s}$ paying attention to not dip the two large contacts on top of the electrode; then it was withdrawn at a rate of $15 \mathrm{~cm} \mathrm{~min}^{-1}$. After the drying process, the films were aged at $\mathrm{RH} \approx 50 \%$ and room temperature for $24 \mathrm{~h}$. The samples were firstly dried in air at $60{ }^{\circ} \mathrm{C}$ in an oven for 1 hour and then annealed at two different temperatures (200 or
$350{ }^{\circ} \mathrm{C}$ ) for 3 hours in air. Titania powders, both dense and mesoporous, were prepared for measuring the porosity and surface area. At first the precursor sols were cast on Petri dishes to obtain thick films by slow evaporation of the solvent at $25{ }^{\circ} \mathrm{C}$ and $30 \% \mathrm{RH}$. The materials were then transferred into crucibles, dried for 1 hour in an oven in air and annealed in an oven for 3 hours at 200 or $350{ }^{\circ} \mathrm{C}$, respectively.

\section{Material characterization}

FTIR. Fourier-transform infrared (FTIR) analysis was performed with an interferometer Bruker infrared Vertex 70v. Spectra were recorded using thin films deposited on silicon in transmission mode between 4000 and $400 \mathrm{~cm}^{-1}$ by averaging 128 scans with $4 \mathrm{~cm}^{-1}$ resolution. The background was measured on a clean silicon wafer substrate; the baseline was fitted by a concave rubber band with OPUS 7.0 software.

Spectroscopic ellipsometry. A Wollam- $\alpha$ spectroscopic ellipsometer with fixed angle geometry was used for the thickness measurements of the thin films deposited on silicon substrates. The thickness was estimated by fitting the experimental data with a Cauchy model for transparent films on $\mathrm{Si}$ substrates. The Cauchy parameters were at first calculated using dense titania films deposited on silicon, then the thickness and porosity were adjusted to achieve the best fit.

Porosimetry. Adsorption and desorption isotherms were recorded by using a Quantachrome Autosorb iQ-MP automated gas sorption analyser and nitrogen as the probe gas at a temperature of $77 \mathrm{~K}$. Analyses were performed on titania powders, mesoporous and dense samples. Before the gas sorption analysis, powders treated at $350{ }^{\circ} \mathrm{C}$ were outgassed at $300{ }^{\circ} \mathrm{C}$ for 3 hours while powders treated at $200{ }^{\circ} \mathrm{C}$ were outgassed at $150{ }^{\circ} \mathrm{C}$ for 12 hours.

X-ray diffraction. X-ray diffraction (XRD) patterns were recorded using a standard Bragg Brentano $(\omega / 2 \theta)$ configuration on a Panalytical Empyrean diffractometer equipped with a graphite monochromator on the diffracted beam and an $\mathrm{X}$ 'Celerator linear detector using $\mathrm{Cu}-\mathrm{K}_{\alpha}, \lambda=0.15418 \mathrm{~nm}$. Crystalline phases were identified using the JCPDS Powder Diffraction File database PDF-2 (International Centre for Diffraction Data, Swarthmore, PA). The average crystallite size was calculated using the Scherrer formula corrected from instrumental broadening determined using a $\mathrm{LaB}_{6}$ standard.

Transmission electron microscopy. Transmission electron microscopy (TEM) images were obtained by using a FEI TECNAI 200 operating at $200 \mathrm{kV}$ working with a field emission electron gun. Before analysis, the films were detached from the substrates using a scalpel blade and the resulting fragments were dispersed in ethanol by ultrasonication for 5 minutes. Afterwards, the ethanol solution was dropped onto silicon copper grids and the solvent was left to evaporate for 3 minutes before the measurements. We have used lacey reinforced grids made by silicon monoxide (Formar stabilized) on copper (Nanovision supplier).

Gas sensing assessment. Samples were inserted into a measurement chamber and connected to a Keithley Model 595 Quasistatic CV Meter to monitor changes in flowing current

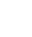




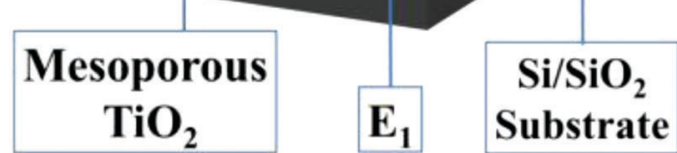

Fig. 1 Schematic of the experimental set-up used for the evaluation of the gas sensing properties.

while keeping a fixed voltage polarization. An ultraviolet light emitting diode (UV LED, LZ1-00U600, $\lambda=365 \mathrm{~nm}$, power

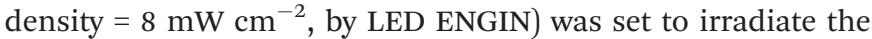
system over all the measurements. Different oxygen concentrations in a mix of air in a nitrogen carrier (purified gas cylinders by Rivoira) were delivered inside the system by using a gas delivery device consisting of a set of mass flow controllers MKS 147B. Measurements were performed under dry conditions at $25{ }^{\circ} \mathrm{C}$ and $200 \mathrm{sccm}$ (standard cubic centimetres per minute), equal to $209 \mathrm{ppm}$, of total gas flow. The experimental set-up is shown in Fig. 1. A UV emitting LED was placed above an interdigitated electrode covered by a thin titania film and the current was measured by using the E1 and E2 electrical contacts.

\section{Results and discussion}

A careful characterization of the titania mesoporous layers has been performed to correlate the sensing response with the physical-chemical properties. The properties of not-templated titania films with those of the block-copolymer-templated samples (hereinafter called "dense" and "mesoporous" in spite of the thermal treatment and the pore accessibility) have been also compared to get a better insight into the material structure-sensing performance relationship.

The thickness of the mesoporous and dense titania films after thermal treatment at 60,200 and $350{ }^{\circ} \mathrm{C}$ is shown in Fig. 2. Mesoporous films treated at $350{ }^{\circ} \mathrm{C}$ have a thickness, $202 \mathrm{~nm}$, This effect is due to the micelles formed during the template selfassembly. The thermal treatment after drying, which is necessary to remove the surfactant in the mesoporous samples and stabilize the oxide structure by promoting densification, induces a significant shrinkage of the films by reducing their thickness by around $50 \%$, both in the mesoporous and dense films. The thickness shrinkage in mesoporous films shows a linear trend; the linear correlation between the firing temperature and the shrinkage, as previously described, ${ }^{24}$ is an indication of the stability of the porous structure within the considered firing range. Collapsing of the porous structure would result in a deviation from linear shrinkage.

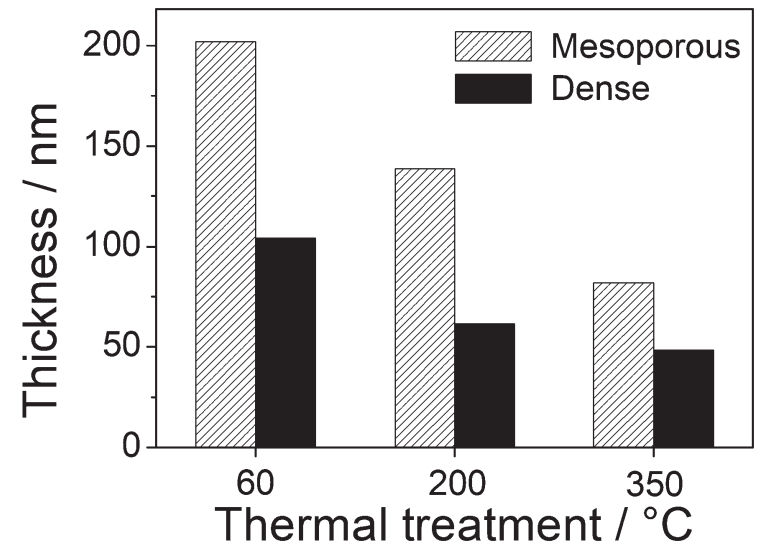

Fig. 2 Thickness of mesostructured and dense titania samples (patterned and black bars, respectively) treated at 60,200 and $350{ }^{\circ} \mathrm{C}$.

FTIR spectroscopy has been used to evaluate the removal of the organic template by thermal treatment of the surface state of the titania films. Drying $\left(60{ }^{\circ} \mathrm{C}\right)$ and densification thermal stages $\left(200\right.$ and $\left.350{ }^{\circ} \mathrm{C}\right)$ are expected to remove the residual water and organic template and to condensate the oxide structure. Fig. 3a and b show the FTIR absorption spectra, in the $3650-2800 \mathrm{~cm}^{-1}$ range, of dense and mesoporous samples after the different thermal treatments. The wide absorption band peaking around $3300 \mathrm{~cm}^{-1}$, observed in the mesoporous and dense samples after drying, is assigned to $-\mathrm{OH}$ stretching. This band shows overlapped signals around $3200 \mathrm{~cm}^{-1}$ due to $-\mathrm{OH}$ stretching in water. After the first thermal treatment, the samples are not yet condensed, as shown by the intense signal of $-\mathrm{OH}$ in the oxide structure while the highly hydrophilic structure absorbs a large amount of water.

The mesoporous samples show further absorption bands between 3000 and $2800 \mathrm{~cm}^{-1}$, which are the signature of the templating surfactant. These bands are assigned to the stretching of the surfactant methylene bridge $-\mathrm{CH}_{2}-$ and the methyl group $\mathrm{CH}_{3}$. To elaborate, the methyl group of the isopropylene block has two characteristic absorption bands at 2970 and 2875 $\mathrm{cm}^{-1}$ due to, respectively, the asymmetrical and symmetrical stretching of the methyl groups. The two absorptions at 2925 and $2855 \mathrm{~cm}^{-1}$ are related to the asymmetrical and symmetrical stretching of the methylene. The spectra show the complete removal of the template after firing at $350{ }^{\circ} \mathrm{C}$. On the other hand, with respect to the dense titania samples, a small amount of $-\mathrm{OH}$ groups is still present because of the incomplete condensation of the films. The shift of the $-\mathrm{OH}$ absorption bands to higher wavenumbers in the films treated at higher temperatures indicates that the surface hydroxyls form chains of smaller length in the process of condensation.

The surface area of the sample has been studied by $\mathrm{N}_{2}$ physisorption (Fig. 4). In general, the isotherms can be classified as Type IV, featured by the hysteresis loop due to the capillary condensation in mesopores and the limiting uptake over a range of high $P / P_{0} \cdot{ }^{25}$ In the intermedium range of the isotherm, the hysteresis loops of the mesoporous samples treated at $200{ }^{\circ} \mathrm{C}$ and $350{ }^{\circ} \mathrm{C}$ (Fig. 4a and b) show branches 

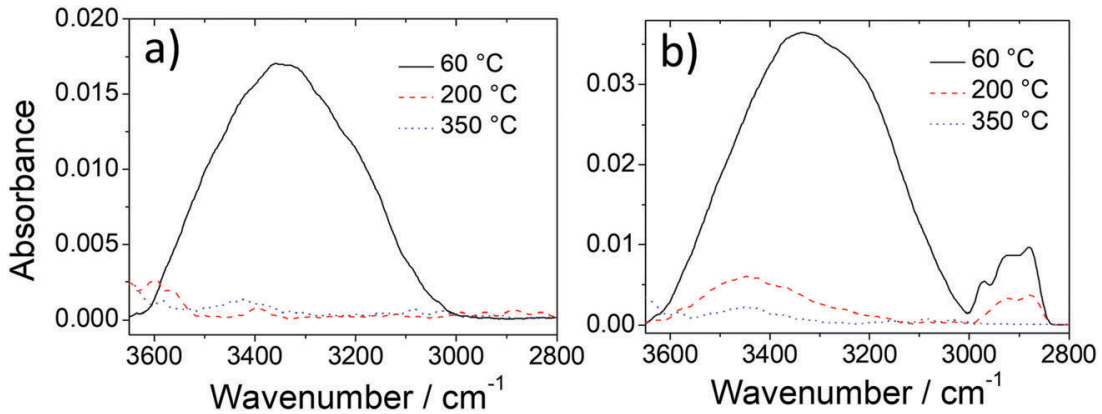

Fig. 3 (a) FTIR absorption spectra of titania films treated at increasing temperatures (black line $60{ }^{\circ} \mathrm{C}$, red dash line $200{ }^{\circ} \mathrm{C}$ and blue dot line $350{ }^{\circ} \mathrm{C}$ ). (b) FTIR spectra of mesostructured titania films treated at increasing temperatures (black $60{ }^{\circ} \mathrm{C}$, red dash line $200{ }^{\circ} \mathrm{C}$ and blue dot line $350{ }^{\circ} \mathrm{C}$ ).

15 almost vertical and nearly parallel, typical of a Type H1 hysteresis and characteristic of a material with a narrow pore size distribution. In contrast, the hysteresis loop of the dense sample treated at $350{ }^{\circ} \mathrm{C}$ can be classified as Type $\mathrm{H} 2$, due to being a structure with not well-defined pore size and shape. Surface area measurements have been done according to the Brunauer-Emmett-Teller theory. The surface area of the mesoporous sample treated at $350{ }^{\circ} \mathrm{C}$, as calculated in the $0.05-0.3 \mathrm{P} /$ $P_{0}$ range, is 2.5 times larger than that of the dense sample treated at the same temperature, $223 \mathrm{~m}^{2} \mathrm{~g}^{-1}\left(R^{2}=0.999\right) v s .89$ $\mathrm{m}^{2} \mathrm{~g}^{-1}\left(R^{2}=0.999\right)$. On the other hand, the templated sample treated at $200{ }^{\circ} \mathrm{C}$ shows a surface area of $45 \mathrm{~m}^{2} \mathrm{~g}^{-1}\left(R^{2}=0.999\right)$ which is half that of the dense film at $350{ }^{\circ} \mathrm{C}$. Thus, the pore size distribution was calculated using the method of BarrettJoyner-Halenda (BJH). The total pore volume of the dense 0 sample treated at $350{ }^{\circ} \mathrm{C}$ is similar to the one of the mesoporous film treated at $200{ }^{\circ} \mathrm{C}$; however it is due to a completely different pore structure (Fig. $4 \mathrm{a}$ and b). In the first case, the pore volume can be attributed to the random packing of the neighbouring nanocrystals nucleated during the film processing; the resultant material is characterized by small channels with a volume of $0.10 \mathrm{~cm}^{3} \mathrm{~g}^{-1}$ and a pore radius of approximately $2.2 \mathrm{~nm}$. In the second case, the porous structure is produced by the partial exposure of the ordered mesopores templated in the titania matrix by the block-copolymers. The

40 so-obtained pores have a radius of $\sim 4.8 \mathrm{~nm}$ and a pore volume of around $0.1 \mathrm{~cm}^{3} \mathrm{~g}^{-1}$. Despite the difference in pore radius, both samples share a similar pore volume since the channels in the templated one are still partially filled with micelles after the thermal treatment at $200{ }^{\circ} \mathrm{C}$, according to previous results. ${ }^{22}$

The effect of the residual templates in the mesopores is also clearly observed considering the $\mathrm{BJH}$ pore size distribution of the mesoporous sample treated at $350{ }^{\circ} \mathrm{C}$ (Fig. 4c), where the organic surfactant is completely thermally removed from the pores. The resulting material is characterized by a pore volume average pore radius of $4.8 \mathrm{~nm}$. Further analysis of the pore radius distribution of this sample (Fig. $4 \mathrm{c}$ inset), taken from the desorption branch, supports the presence of a broad polydispersion of pore size which has been already observed in locally ordered mesoporous materials and can be attributed to a not completely organized pore structures. The $\mathrm{H} 2$ type hysteresis of the adsorption/desorption isotherm curve, however, does not provide a clear indication about the pore structure as it can be due either to a wide distribution of independent pores with the same or similar neck or a network where the neck size distribution is much more narrow than the size distribution of the main cavities. ${ }^{26}$ It has to be underlined that the porosity of dried powders obtained through evaporation induced selfassembly exhibits a strong dependence on the processing conditions, such as temperature, atmosphere, $\mathrm{RH} \%$, drying rate $^{27}$ and in general is not affected by the uniaxial shrinkage under thermal treatment which is typical of mesoporous thin films. The present samples have been however prepared under the same conditions and a comparison of the different porosities and surface areas gives a good indication of the correlated differences in the thin film samples. The surface area, pore volume and radius of the three samples are reported in Table 1.

The TEM images in Fig. 5, highlight the different pore structures as a function of thermal processing and template removal. The top-view TEM micrograph of the dense sample treated at $350{ }^{\circ} \mathrm{C}$ (Fig. 5a) reveals a high degree of porosity homogeneously dispersed throughout the whole material. These pores have a lower electron density with respect to the pore walls and therefore result in being almost transparent to the electrons. ${ }^{28}$ The lack of structure directing agents has induced the formation of a porous network characterized by the prevailing asymmetrical arrangements. Differently, the porous array of the templated thin film treated at $200{ }^{\circ} \mathrm{C}$ (Fig. 5b) can be described as a so-called "modulated channel pattern". This specific pattern derives from the projection of superimposed pores of [110] planes orthogonally oriented to the surface. ${ }^{29}$ The resulting architecture consists of a body centered cubic structure with $\operatorname{Im} 3 m$ ordered domains in the $z$ direction. Finally, the TEM image of the templated thin film treated at $350{ }^{\circ} \mathrm{C}$ (Fig. 5c) shows an arrangement of pores which are homogeneously distributed within the matrix and have a similar size although the long-range pore order distinctive of the "modulated channel pattern" appears to be replaced by a shortrange order because of the higher temperature processing.

The XRD patterns of the mesoporous and dense films treated at $350{ }^{\circ} \mathrm{C}$ show a diffraction peak at $25.7^{\circ}$, which has been considered as consistent with the (101) reflection of the $\mathrm{TiO}_{2}$ anatase, and a faint broad peak around $38.5^{\circ}$, which has been attributed to the merging of the triplet at $37.5^{\circ}$ (103), $38.4^{\circ}$ 


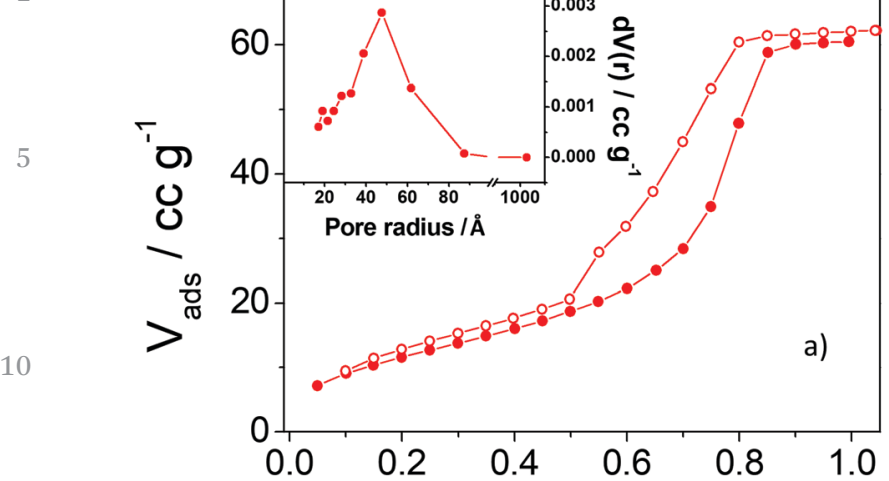

Fig. $4 \quad \mathrm{~N}_{2}$ physisorption isotherms and pore size distribution plots for the mesoporous titania samples treated at $200{ }^{\circ} \mathrm{C}(\mathrm{a})$, the dense and mesoporous samples treated at $350{ }^{\circ} \mathrm{C}$ (b and c). The pore size distributions calculated from the physisorption isotherms are reported as insets.

(004) and $39.2^{\circ}$ (112) of the same phase. The diffraction patterns of the different samples show that nanocrystalline titania is detectable only in the films treated at $350{ }^{\circ} \mathrm{C}$ and the peak broadening is larger for the mesoporous titania with respect to the not-templated sample, indicating the occurrence of smaller crystalline domains. The Scherrer formula applied to the (101) peak has allowed estimating the crystallite average sizes at $11 \pm 2$ and $21 \pm 2 \mathrm{~nm}$ for the mesoporous and dense films, respectively. The Scherrer formula provides an indicative value of the average crystalline domain size although it is well
Table 1 BET (Brunauer, Emmett, Teller) surface area, BJH (Barrett, Joyner, Halenda) pore volume and radius of the titania samples

\begin{tabular}{lcll}
\hline & & \multicolumn{1}{l}{ BJH } & \\
\cline { 4 - 5 } Samples & area $\left(\mathrm{m}^{2} \mathrm{~g}^{-1}\right)$ & Pore volume $\left(\mathrm{cm}^{3} \mathrm{~g}^{-1}\right)$ & Pore radius $(\mathrm{nm})$ \\
\hline $200{ }^{\circ} \mathrm{C}$ meso & 45 & 0.09 & 4.8 \\
$350{ }^{\circ} \mathrm{C}$ dense & 89 & 0.10 & 2.2 \\
$350{ }^{\circ} \mathrm{C}$ meso & 223 & 0.32 & 4.8
\end{tabular}

known that there might be additional factors, such as strain effects, which can affect the diffraction profile.

The photoconductive response of the titania films has been measured by irradiating the samples with a UV lamp and simultaneously recording the electrical current variations $(A)$ at a fixed voltage $\left(V_{\mathrm{d}}=100 \mathrm{mV}\right)$ while changing the oxygen concentration in the experimental chamber. An example of the current variation as a function of UV irradiation time $(\lambda=$

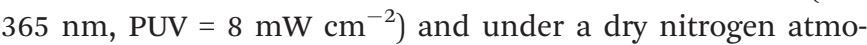
sphere is shown in Fig. 6. The current exponentially increases to $\sim 0.55 \mu \mathrm{A}$ and reaches a steady value after $\sim 25000 \mathrm{~s}$ of $\mathrm{UV}$ irradiation. The rise of the electric charge flow is due to the photoconductive effect. ${ }^{30}$ This phenomenon, because of the electromagnetic radiation absorption by a semiconductor, increases the number of free electrons and holes, raising the electrical conductivity of the material. On the other hand, different dynamics associated with this carrier photogeneration and the processes of recombination or trapping for instance can decrease the electrical conductivity in the material over time. Candidates for electron trapping include the superficial hydroxylated $\mathrm{Ti}$ sites, easily reduced to $-\mathrm{Ti}(\mathrm{III})-\mathrm{OH} .{ }^{31}$

The electrical response of the titania films has been explored by changing the voltage of the flowing current. Fig. 7 shows the response of the mesostructured sample treated at $350{ }^{\circ} \mathrm{C}$. These experiments have been realized under a stream of dry nitrogen (209 ppm) and constant UV irradiation. The electrical steady state current versus voltage curve has a linear response, suggesting the presence of an ohmic contact between the metallic electrode and the sensing layer.

Afterwards, the interactions between gaseous oxygen and titania thin films have been evaluated within the measurement chamber, at room temperature, dry atmosphere and under UV irradiation. The device bias voltage has been kept under constant control at the set value of $100 \mathrm{mV}$ to avoid possible material degradation.

The electrical device response has been assessed in terms of relative current $I / I_{0}$, with $I$ as the electrical current registered at a specific time and oxygen concentration and $I_{0}$ as the value registered under a nitrogen atmosphere at the beginning of the experiment, when the system and the voltage are considered to be in equilibrium. Fig. 8 shows the dynamic response of the different titania samples measured over increasing steps of oxygen injection.

The adsorption and desorption response times (evaluated between $10 \%$ to $90 \%$ of the signal) are $180 \mathrm{~s}$ for oxygen concentrations lower than $500 \mathrm{ppm}$. For higher concentrations the response times increase up to $600 \mathrm{~s}$. The response is not linear in the range 50 to $1100 \mathrm{ppm}$, therefore we have calculated 

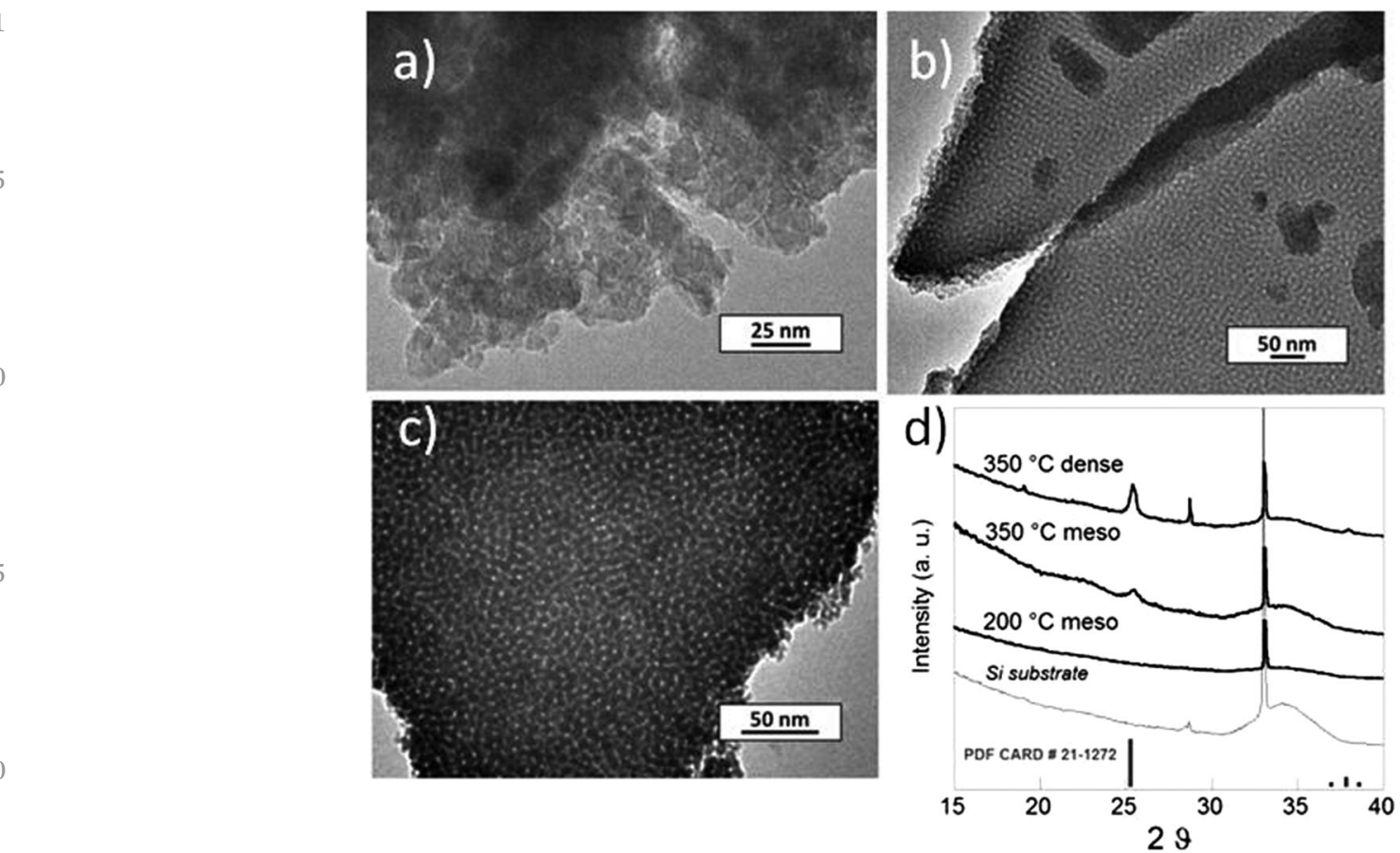

Fig. 5 TEM pictures of a dense sample treated at $350{ }^{\circ} \mathrm{C}$ (a); a templated titania film thermally treated at $200{ }^{\circ} \mathrm{C}$ (b) and a mesoporous titania film treated at $350{ }^{\circ} \mathrm{C}$ (c). (d) XRD patterns of the titania films and silicon substrate: dark grey bars indicate the $\mathrm{TiO}_{2}$ anatase peaks as from PDF cards $21-1272$.

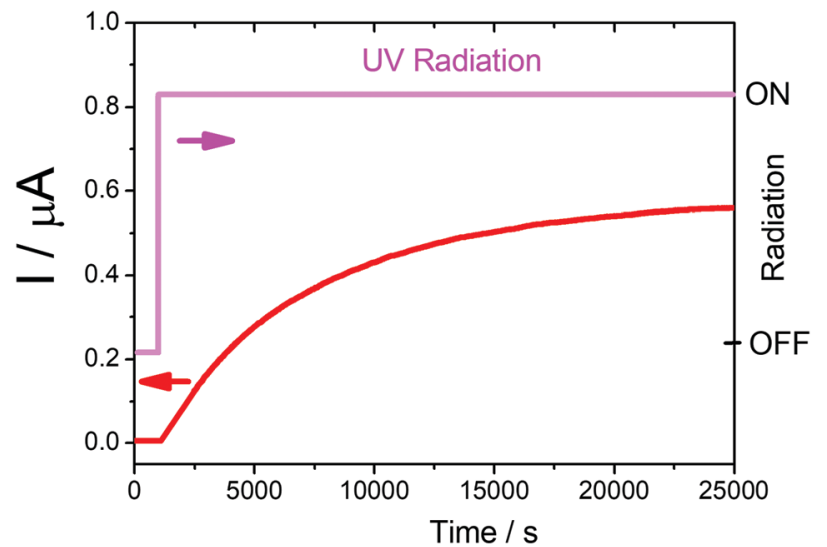

40

Fig. 6 Current variation as a function of UV irradiation for the mesostructured sample treated at $350{ }^{\circ} \mathrm{C}$. Electrical current variation was recorded at a fixed voltage $\left(V_{d}=100 \mathrm{mV}\right)$.

the sensitivity for concentrations higher than 400 ppm where response shows a linear behaviour. The sensitivity value, calculated as $\mathrm{d}\left(I / I_{0}\right) / \mathrm{d} C$ with $C$ indicating the oxygen concentration in ppm, was about $0.12 \times 10^{-3} \mathrm{ppm}^{-1}$ with a resolution of $180 \mathrm{ppm}$. The limit of detection was about 5 ppm using a signal to noise ratio equal to 3 .

The electrical response due to the reaction of a semiconducting metal oxide with gaseous species is due to several parameters, pre-treatment of the sample and its reduction state, degree of surface hydroxylation, and the presence of different acceptor or donor species. In the titania samples, because the measures have been performed under an inert nitrogen atmosphere the reactions can be correlated only to the

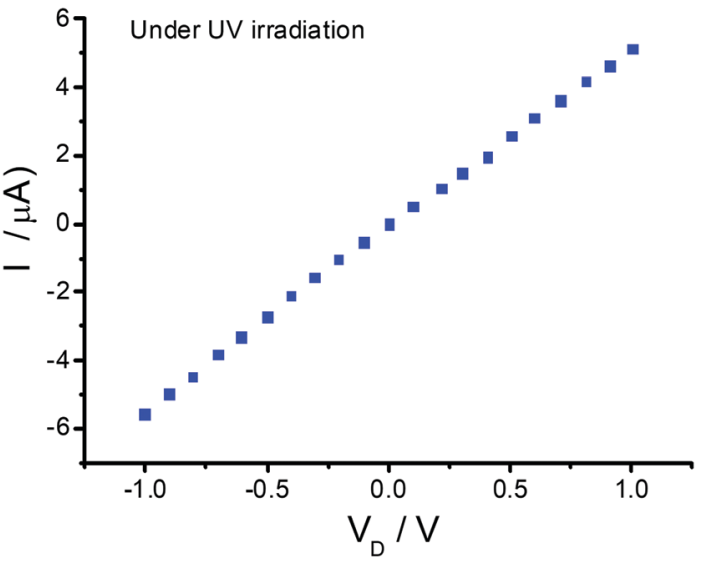

Fig. 7 Electrical current vs. voltage under constant UV radiation and a dry nitrogen atmosphere for a mesostructured thin film treated at $350{ }^{\circ} \mathrm{C}$

constituent transducer and the benchmark gaseous molecules. In the specific case of molecularly adsorbed oxygen molecules, they generally act as electron scavengers, ${ }^{27,32}$ depleting the electric current flowing through the semiconducting oxide and causing a decrease of the ratio $I / I_{0}$. This depletion effect can be recognized by an initial and sudden drop in the current flowing through the sample. The injection of oxygen at fixed concentrations causes a decrease of current flow up to a minimum and then the current restarts flowing linearly but at a lower intensity. Further injections of oxygen should cause similar and additive results. However, as shown in Fig. 4 and 5, the structure of the sensing material and the surface area affect the electrical signal changes in a different way (Fig. 8). 


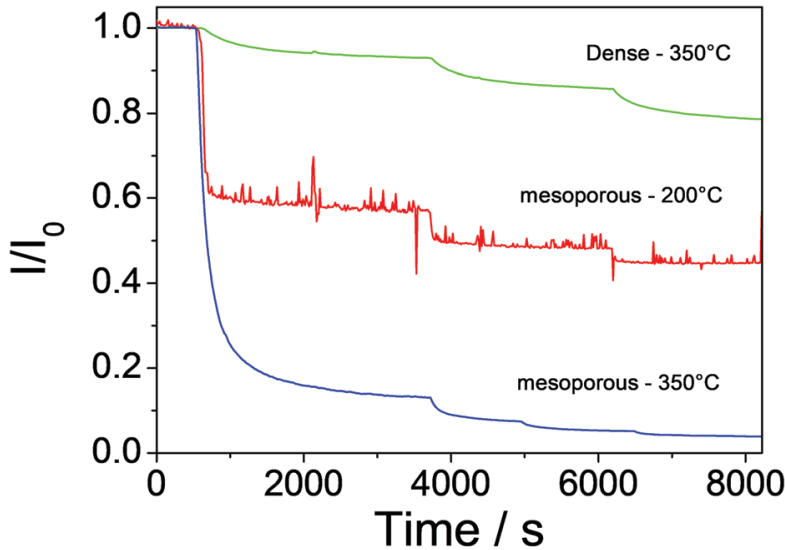

Fig. 8 Dynamic response of mesoporous titania films treated at 200 and $350{ }^{\circ} \mathrm{C}$. The samples have been exposed to UV radiation and growing $\mathrm{O}_{2}$ concentrations while under a dry nitrogen atmosphere. The $350{ }^{\circ} \mathrm{C}$ dense titania sample is used as reference. The concentration steps were 209 ppm at $500 \mathrm{~s}, 400 \mathrm{ppm}$ at $3700 \mathrm{~s}$ and $600 \mathrm{pm}$ at $6300 \mathrm{~s}$.

Mesoporous titania samples thermally treated at $350{ }^{\circ} \mathrm{C}$ show a remarkable response while interacting with oxygen that is due to their specific structure and surface area. Despite both mesoporous and dense titania thin films at $350{ }^{\circ} \mathrm{C}$ being characterised by a nano-crystalline anatase structure, the mesoporous sample shows a decrease in electrical current of nearly $90 \%$ after being exposed to 209 ppm of oxygen; in contrast, the dense sample has a reduction in electrical current of only $7 \%$ under the same conditions. Additional and controlled injections of oxygen cause minimal decrements of $4-3 \%$ at each step in dense samples, and a decrease of $10 \%$ in the mesoporous titania. On the other hand, the films treated at $200{ }^{\circ} \mathrm{C}$ have a higher sensitivity to oxygen than the dense sample treated at $350{ }^{\circ} \mathrm{C}$. $I / I_{0}$ falls to $57 \%$ when exposed to $209 \mathrm{ppm}$ of oxygen, in spite of its lower crystallinity and specific surface area. Furthermore, both mesoporous samples show a similar reaction profile, with a sudden decrease after the first flow of oxygen. Additional oxygen injections cause a drop of the electrical current with a decreasing effect as the gas concentration increases. It has been proposed that the chemisorbed oxygen molecules transform into various anion species by scavenging electrons from the titanium dioxide structure according to the following processes (eqn (1)): ${ }^{33}$

$\mathrm{O}_{2(\text { gas })} \Leftrightarrow \mathrm{O}_{2(\mathrm{ad})} \Leftrightarrow \mathrm{O}_{2(\mathrm{ad})}{ }^{-} \Leftrightarrow \mathrm{O}_{(\mathrm{ad})}{ }^{-} \Leftrightarrow \mathrm{O}_{(\mathrm{ad})}{ }^{2-} \Leftrightarrow \mathrm{O}_{2 \text { (lattice) }}$

In bulk titania, at temperatures higher than $180{ }^{\circ} \mathrm{C}$, the chemisorbed oxygen molecules are predominantly in the form of $\mathrm{O}^{-}$and $\mathrm{O}^{2-}$, causing the formation of a depletion layer on the film surface that enhances the electrical resistance. The remarkable sensitivity shown by the mesoporous titania samples at room temperature, however, cannot be explained without considering the structure at the nanoscale. The dense and mesoporous films, as previously underlined, exhibit an anatase nanocrystalline structure but the dense sample is more crystalline and has a larger crystallite size. This is not reflected, however, in better sensing performances for several reasons, one is that disorder in general provides more favorable photocatalytic performances and the other is that a predominant role in the present case is played by the surface area. In fact, the high surface area provided by the organized mesoporosity accounts for the increased number of defects such as oxygen vacancies or interstitial positions which provide a large number of local donor energy levels. ${ }^{34}$ This produces an enhancement of the material conductivity by increasing the number of charge carriers and enhancing the intrinsic sensitivity of the mesoporous titania as a consequence of the higher dynamic ranges of the conductivity. The different responses between the mesoporous films treated at $200{ }^{\circ} \mathrm{C}$ and the dense sample at $350{ }^{\circ} \mathrm{C}$, therefore, can be justified by considering that, although the accessible surface area of the samples is similar, the number of local donor energy levels is higher in the mesoporous film because of the defects at the micelle/titania interface. The presence of residual and partially decomposed blockcopolymers in the pores affects the sensing properties causing a very high electrical noise in the detection which is not observed for the samples treated at $350{ }^{\circ} \mathrm{C}$ (Fig. 8).

The best sensing performances provided by the mesoporous film at $350{ }^{\circ} \mathrm{C}$, therefore, should be ascribed both to an early crystallization of the matrix, which has been observed in previous studies by using Raman and far infrared spectroscopies, ${ }^{22,35}$ and to the higher surface area accessibility due to the complete surfactant removal. It should be underlined that even in titania samples defined as amorphous small anatase-like domains can be found at temperatures as low as $200{ }^{\circ} \mathrm{C}$ which justify the weak photocatalytic performance. ${ }^{36}$ The combined effect of the crystalline structure (dense sample treated at $350{ }^{\circ} \mathrm{C}$ ) and the organized mesoporosity (mesoporous sample at $200{ }^{\circ} \mathrm{C}$ ) are responsible for a dramatic enhancement of the detection sensitivity as clearly observed by comparing the $I / I_{0}$ fall of the three samples. The similar slope of the $I / I_{0}$ fall observed in the mesoporous sample at 200 and $350{ }^{\circ} \mathrm{C}$ suggests that the mechanism controlling the detection properties, that is the number of surface defects, does not change as a consequence of the higher temperature treatment, even if competing effects cannot be completely ruled out. The different range of $I / I_{0}$ is, therefore, mainly attributed to the improved accessibility of the surface area.

Fig. 9 summarizes how the organization at the mesoscale triggers a different electrical response. The dense film at $350{ }^{\circ} \mathrm{C}$, despite the partially crystallized structure, has a limited conductivity and the smallest $I / I_{0}$ dynamic range. The organization of the micelle in the mesoporous sample treated at $200{ }^{\circ} \mathrm{C}$ accounts for the higher interface of the inorganic matrix, although not completely accessible, leading to a higher number of donor levels and therefore both a higher $I_{0}$ and $I / I_{0}$ range. Finally, the mesoporous titania film fired at $350{ }^{\circ} \mathrm{C}$ has the highest $I_{0}$ and $I / I_{0}$ range because of the improved crystallinity. The large number of donor levels ${ }^{37}$ strongly interact with the environment through the completely accessible surface area.

The dynamic response of the mesoporous sample treated at $350{ }^{\circ} \mathrm{C}$ has been also tested as a function of oxygen concentration in the range between $0 \mathrm{ppm}$ to $1100 \mathrm{ppm}$ (Fig. 10). 
a)

b)

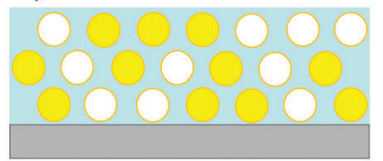

c)

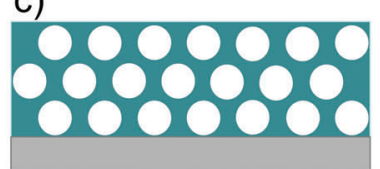

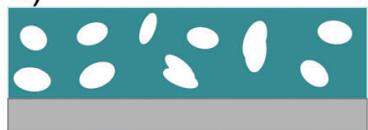

hv

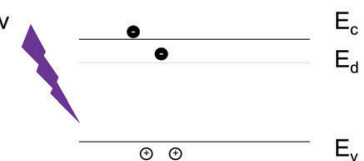

hv

hv

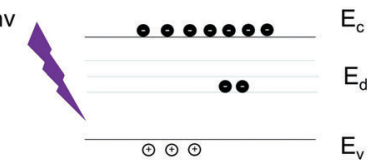

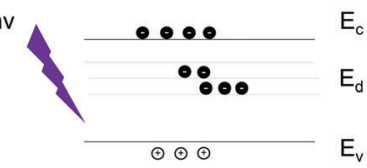

Fig. 9 Schematic of the different conducting properties of titania films as a function of the thermal treatment and the morphology at the mesoscale: (a) dense film treated at $350{ }^{\circ} \mathrm{C}$; (b) mesoporous film treated at $200{ }^{\circ} \mathrm{C}$, (c) mesoporous film treated at $350{ }^{\circ} \mathrm{C}$. The corresponding density of charge carriers is shown in the right column $\left(E_{\mathrm{c}}, E_{\mathrm{d}}\right.$ and $E_{\mathrm{v}}$ are the energy levels of the conduction, donor and valence bands, respectively).

The material structure at the mesoscale is a critical parameter to enhance the sensitivity of mesoporous titania films towards atmospheric oxygen, when irradiated by UV-light. Under UV irradiation nanocrystalline anatase produces a high current flow because of the photoconductive effect. As compared to dense titania films, the presence of the mesostructure promotes an effective diffusion of the oxygen molecules. At the same time the associated larger number of surface defects has a pivotal role in increasing the fall of the current $\left(I / I_{0}\right)$ quenched by the adsorbed oxygen molecules.

Overall, mesoporous titania films treated at $350{ }^{\circ} \mathrm{C}$ exhibit a strong increase in sensitivity with a negligible hysteresis effect and a fast sensing response which can be ascribed to an optimal combination of high surface area and anatase crystallites in the nanoscale. The peculiar properties of the titania mesoporous films open the route to the development of mesoporous titania-based sensors performing at room temperature and which can be fabricated as thin films to be integrated into microelectronic devices.

\section{Conflicts of interest}

\section{Acknowledgements}

RAS is acknowledged for funding this project through CRP 30 L.R. 7/2007 "Bando Capitale Umano ad Alta Qualificazione annualità 2015". This work was partially supported by the project "Mi ADATTI E L'ABBATTI"- INSTM-Regione Lombardia project INSTMRL6.

\section{References}

1 U. Diebold, Surf. Sci. Rep., 2003, 48, 53.

2 A. Tripathy, S. Pramanik, A. Manna, S. Bhuyan, N. F. A. Shah, Z. Radzi and N. A. A. Osman, Sensors, 2016, 16, 1135.

3 R. Moos, N. Izu, F. Rettig, S. Reiß, W. Shin and I. Matsubara, Sensors, 2011, 11, 3439.

4 J. Bai and B. Zhou, Chem. Rev., 2014, 114, 10131.

5 P. T. Moseley, Sens. Actuators, B, 1992, 6, 149.

6 U. Diebold, Surf. Sci. Rep., 2003, 48, 53.

7 L. Gao, Q. Li, Z. Song and J. Wan, Sens. Actuators, B, 2000, $71,179$.

8 A. Takami, Am. Ceram. Soc. Bull., 1988, 67, 1956.

9 D. S. Presicce, L. Francioso, M. Epifani, P. Siciliano and A. Ficarella, Sens. Actuators, B, 2005, 111-112, 52.

10 H. Wang, L. Chen, J. Wang, Q. Sun and Y. Zhao, Sensors, 2014, 14, 16423.

11 P. Falcaro, L. Malfatti, L. Vaccari, H. Amenitsch, B. Marmiroli, G. Grenci and P. Innocenzi, Adv. Mater., 2009, 21, 4932.

12 P. Innocenzi and L. Malfatti, Chem. Soc. Rev., 2013, $42,4198$. 13 L. Malfatti, M. G. Bellino, P. Innocenzi and G. J. A. A. SolerIllia, Chem. Mater., 2009, 21, 2763.

14 A. A. Ismail and D. W. Bahnemann, J. Mater. Chem., 2011, 21, 11686.

15 E. Sotter, X. Vilanova, E. Llobet, A. Vasiliev and X. Correig, Sens. Actuators, B, 2007, 127, 567. 
16 P. Innocenzi, P. Falcaro, J. Mio Bertolo, A. Bearzotti and H. Amenitsch, J. Non-Cryst. Solids, 2005, 351, 1980.

17 P. Falcaro, J. Mio Bertolo, P. Innocenzi, H. Amenitsch and A. Bearzotti, J. Sol-Gel Sci. Technol., 2004, 32, 107.

518 G. S. Devi, T. Hyodo, Y. Shimizu and M. Egashira, Sens. Actuators, B, 2002, 87, 122.

19 D. Grosso, G. J. de, A. A. Soler-Illia, E. L. Crepaldi, F. Cagnol, C. Sinturel, A. Bourgeois, A. Brunet-Bruneau, H. Amenitsch, P. A. Albouy and C. Sanchez, Chem. Mater., 2003, 15, 4562.

1020 A. Walcarius, Chem. Soc. Rev., 2013, 42, 4098.

21 A. Walcarius, Electroanalysis, 2015, 27, 1303.

22 T. Wagner, S. Ahffer, C. Weinberger, D. Klaus and M. Tiemann, Chem. Soc. Rev., 2013, 42, 4036.

23 D. B. Papskovsky and R. I. Dmitriev, Chem. Soc. Rev., 2013, 42, 8700 .

24 D. Carboni, D. Marongiu, P. Rassu, A. Pinna, H. Amenitsch, M. Casula, A. Marcelli, G. Cibin, P. Falcaro, L. Malfatti and P. Innocenzi, J. Phys. Chem. C, 2014, 118, 12000.

25 K. S. W. Sing, D. H. Everett, R. A. W. Haul, L. Moscou, R. A. Pierotti, J. Roquérol and T. Siemieniewska, Pure Appl. Chem., 1985, 57, 603.

26 M. Thommes, Chem. Ing. Tech., 2010, 82, 1059.

27 J. L. Marco-Brown, M. A. Balesa and G. J. A. A. Soler-Illia, Colloids Surf., A, 2017, 530, 93.
28 G. J. A. A. Soler-Illia, P. C. Angelomé, M. C. Fuertes, D. Grosso and C. Boissière, Nanoscale, 2012, 4, 2549.

29 E. L. Crepaldi, G. J. J. A. Soler-Illia, D. Grosso, F. Cagnol, F. Ribot and C. Sanchez, J. Am. Chem. Soc., 2003, 125, 9770.

30 A. M. Eppler, I. M. Ballard and J. Nelson, Phys. E, 2002, 14, 197.

31 E. Konstantinova, J. Weidmann and T. Dittrich, J. Porous Mater., 2000, 7, 389.

32 J. Weidmann, Th. Dittrich, E. Konstantinova, I. Lauermann, I. Uhlendorf and F. Koch, Sol. Energy Mater. Sol. Cells, 1999, 56, 153.

33 M. Batzill and U. Diebold, Prog. Surf. Sci., 2005, 79, 47.

34 D. Kohl, Sens. Actuators, 1989, 18, 71.

35 P. Innocenzi, L. Malfatti, T. Kidchob, S. Enzo, G. Della Ventura, U. Schade and A. Marcelli, J. Phys. Chem. C, 2010, 114, 22385.

36 P. C. Angelomé, L. Andrini, M. E. Calvo, F. G. Requejo, S. A. Bilmes and G. J. A. A. Soler-Illia, J. Phys. Chem. C, 2007, 111, 10886.

37 M. Castellote and N. Bengtsso, Principles of $\mathrm{TiO}_{2}$ Photocatalysis, in Application of Titanium Dioxide Photocatalysis to Construction Materials, ed. Y. Ohama and D. Van Gemert, RILEM State-of-the-Art Reports, vol. 5, 2011.
1 